Bull. Mater. Sci., Vol. 17, No. 6, November 1994, pp. 699-715. (C Printed in India.

\title{
Acoustic emission behaviour during stage II fatigue crack growth in an AISI type 316 austenitic stainless steel
}

\author{
V MOORTHY, T JAYAKUMAR and BALDEV RAJ \\ Division for PIE and NDT Development, Indira Gandhi Centre for Atomic Research, \\ Kalpakkam 603 102, India
}

\begin{abstract}
Acoustic emission (AE) behaviour during fatigue crack growth (FCG) in a ductile AISI type 316 austenitic stainless steel is reported. The two substages in the stage II Paris regime of FCG could be distinguished by a change in the rate of acoustic activity with increase in crack growth rate. The transition point in the cumulative ringdown count plot coincides with that in the $\mathrm{d} a / \mathrm{d} n$ plot. The $\mathrm{AE}$ activity increases with increase in $\Delta K$ during stage lla and decreases during stage llb. The major source of $\mathrm{AE}$ during stage Ila is found to be the plastic deformation within the cyclic plastic zone (CPZ) as compared to the phenomena such as monotonic plastic zone (MPZ) expansion, ductile crack growth, crack closure, etc. The increase in $\mathrm{AE}$ activity with increase in $\Delta K$ during stage IIa is attributed to the increase in the size of the CPZ which is generated and developed only under plane strain conditions. The decrease in AE activity during stage IIb is attributed to the decrease in the size of the $\mathrm{CPZ}$ under plane stress condition. The high acoustic activity during the substage lla is attributed to irreversible cyclic plasticity with extensive multiplication and rearrangement of dislocations taking place within the CPZ. The AE activity is found to strongly depend on the optimum combination of the volume of the $\mathrm{CPZ}$, average plastic strain range and the number of cycles before each crack extension. Based on this, an empirical relationship between the cumulative RDC and $\Delta K$ has been proposed and is found to agree well with experimentally observed values.
\end{abstract}

Keywords. Acoustic emission; ringdown counts; fatigue crack growth; cyclic plastic zone; AISI type 316 stainless steel.

\section{Introduction}

Development of a reliable non-destructive method for detection, location and measurement of the propagation rate of dynamic subcritical flaws is useful for predicting the integrity of a component thereby increasing its duration of safe operations. Acoustic emission technique (AET) is widely used for understanding plastic deformation mechanisms (Heiple and Carpenter 1987) and crack growth mechanisms (Mori et al 1980; Daniel Smith and Carpenter 1988). A study by Mori et al (1980) showed that acoustic emission (AE) activity can be correlated to various sources such as plastic deformation near the crack tip, microcracking, intergranular facet formation etc. Another study by Smith et al (1988) on the analysis of $\mathrm{AE}$ energy and frequency content of $\mathrm{AE}$ signals reveals that the sources produce distinct $\mathrm{AE}$ signatures (wave characteristics). It is possible to identify the type of $\mathrm{AE}$ sources such as fracture of inclusions, transgranular and intergranular cleavage etc from these signatures. Several attempts have been made to use AET for monitoring crack growth in materials and components manifesting hydrogen embrittlement and stress corrosion (Dunegon and Tetelman 1971; Hartbower et al 
1972; Hideo Kusanagi et al 1980). It has been observed that AET gives useful information for studying crack growth and giving new insight into fracture mechanisms. The feasibility of using AET for crack growth measurement has been studied by Gerberich and Hartbower (1967) and Hartbower et al (1968). But, these investigations on $\mathrm{AE}$ from fatigue crack growth (FCG) have been confined mainly to crack growth rates greater than $10^{-5} \mathrm{~m} /$ cycle which is towards the higher end of crack growth rates encountered in engineering structures. A study by Dunegan et al (1968) showed a power law relationship between total number of AE signals $(N)$ resulting from the plastic deformation near the crack tip and the stress intensity factor $(K)$ as $N=A K^{m}$. Experimental results show that the value of $m$ ranges from 4 to 8 for different materials. This study established that it should be possible to continuously monitor slow crack growth by AE, if we could establish the parameters $A$ and $m$ for a given material of particular thickness. Followed by these investigations, several attempts have been made to use AET for studying high cycle fatigue crack growth on different materials. These studies have resulted in establishing relationships between $\mathrm{AE}$ parameters such as cumulative $\mathrm{AE}$ ringdown counts, count rate (counts/cycle) with fatigue parameters such as stress intensity factor range $(\Delta K)$, crack growth rate (da/dn) etc (Dunegan et al 1970; Morton et al 1973; Harris and Dunegan 1974; Lindley et al 1978; Mori et al 1980; Ohira et al 1980; Hamel et al 1981). All these investigations suggest that AET has a great potential for its use as an in-service inspection method. AET, which gives information on the dynamic changes such as plastic deformation and crack propagation, can be applied for continuous monitoring of fatigue crack growth.

Many researchers have reported that the FCG behaviour differs between the initial and later parts of the linear stage II Paris curve (Birkheck et al 1971; Gurevich and Edidorich 1974; Moorthy et al 1991). It has been suggested that stage II region can be divided into two substages, IIa and IIb (Masuda et al 1980; Grinberg 1984). Stage IIa corresponds to structure sensitive slow crack propagation and constitutes a microcrack advance after a certain number of cycles. During stage IIb, the crack propagation is insensitive to submicroscopic structural features and the crack propagates with every load cycle. Hence, a significant difference in the FCG rate and the associated acoustic emission (AE) behaviour between stages IIa and IIb is expected.

In the earlier acoustic emission studies, the phenomena such as crack growth (Harris and Dunegan 1974; Paul Mclintire 1987), crack closure (Wang et al 1992) and plastic deformation occurring near the crack tip (Palmer 1973; Lindely et al 1978) have been considered as the sources of AE. In most of the earlier studies on AE during FCG (Morton et al 1973; Harris and Dunegan 1974; Ohira et al 1980; Hamel et al 1981), only the AE signal generated near the peak load was used for analysis, considering that crack growth occurs only near the peak load. However, it is well known that the ductile crack growth is a very weak source of AE (Palmer 1973; Paul Mclintire 1987). Also in the pure FCG process, the damage is not induced by $K_{\max }$, but only by the relevant $\Delta K$ (Moura Branco et al 1989). The damage induced by $\Delta K$ in any one cycle will be added to the damage accumulated during the previous cycles and it is due to this additive process that FCG occurs after attaining critical strain at the crack tip. In the case of ductile materials, the cyclic plasticity is considered as the main damage process (Davidson and Lankford 1983). The irreversible cyclic plasticity within the cyclic plastic zone 
occurs even at lower load level throughout the fatigue cycle. The plasticity is associated with extensive dislocation generation and rearrangement. Hence, collecting only the peak load $\mathrm{AE}$ is not likely to give information about the overall $\mathrm{AE}$ sources which contribute to the fatigue damage mechanism. Therefore, particularly for ductile materials, the AE generated during the entire fatigue cycle should be acquired to get the information from all possible sources of AE. This data acquisition is thought to be essential to analyze the extent of contribution from all the possible $\mathrm{AE}$ sources and finally to establish the main source of $\mathrm{AE}$ so that a better insight into the relationship between $\mathrm{AE}$ behaviour and fatigue mechanisms can evolve. Authors are not aware of any such attempts reported by any other investigators. Also, there is no study reported in the literature to analyze $A E$ behaviour during the two substages IIa and IIb. The objective of the present investigation is to study the AE behaviour during stage II FCG in an AISI type 316 stainless steel and establish the major source of $\mathrm{AE}$ during fatigue crack propagation, by collecting and analyzing $\mathrm{AE}$ generated throughout the loading cycle. It is also intended to predict the relationship between the $\mathrm{AE}$ parameter and the cyclic stress intensity factor $\Delta K$.

\section{Experimental}

Nuclear grade AISI type 316 stainless steel compact tension (CT) specimens of 25 $\mathrm{mm}$ and $12.5 \mathrm{~mm}$ thicknesses and having chevron notch were fabricated according to the ASTM standard E647-86 (1986). Two different thickness specimens were used to study the influence of specimen thickness on the $\mathrm{AE}$ behaviour. Typical chemical composition of the steel is as follows: $\mathrm{Ni}: 12.43 \%, \mathrm{Cr}: 16.46 \%, \mathrm{Mo}$ : $2.28 \%$, C: $0.054 \%, \mathrm{Mn}: 1.69 \%$, Si: $0.64 \%$, S: $0.006 \%$, P: $0.02 \%$, Fe: Rest. All the specimens were solution-annealed at $1323 \pm 5 \mathrm{~K}$ for $1 \mathrm{~h}$ in vacuum better than $10^{-5}$ torr $\left(133 \times 10^{-5} \mathrm{Nm}^{-2}\right)$. The average grain size of the microstructure is $50 \mu \mathrm{m}$. The yield stress and ultimate tensile stress of the material were measured as $270 \mathrm{MPa}$ and $580 \mathrm{MPa}$ respectively. All the specimens were fatigue precracked according to the ASTM standard E 647 (1986) in a MTS model 811 closed loop servo hydraulic testing system. The precracked specimens were subjected to constant amplitude tension-tension cyclic loading in the load range of $1-10 \mathrm{kN}$ at $25 \mathrm{~Hz}$ frequency. The surface crack length was measured to an accuracy of $0.01 \mathrm{~mm}$ using a $10 \times$ travelling microscope at different stages of its propagation. The test was interrupted for this purpose.

The $\mathrm{AE}$ generated during the fatigue test was acquired using a $375 \mathrm{kHz}$ resonant piezoelectric sensor. This sensor frequency was found to be optimum with minimum interference from the servo hydraulic system noise. Teflon coated loading pins were used in order to reduce the noise due to rotating pins. The constant force spring loaded sensor was coupled to the surface of the specimen with high vacuum grease. The acquired AE signals were amplified by a $40 \mathrm{~dB}$ fixed gain preamplifier. A bandpass filter having a range of $250-500 \mathrm{kHz}$ was used. The preamplified and filtered AE signals were further amplified and analyzed using model AET 5000 $\mathrm{AE}$ system. The overall gain selected was $65 \mathrm{~dB}$. The threshold selected was $0.8 \mathrm{~V}$ which was just above the background noise level. A dummy CT specimen without notch was fatigue cycled between $1-10 \mathrm{kN}$ load range at $25 \mathrm{~Hz}$ frequency. This 
dummy test showed that the contribution from external noises such as rotating pins, grip noises etc to the recorded $\mathrm{AE}$ is insignificant under the experimental conditions selected. This is attributed to the low frequency of AE signals generated by these noise sources as compared to the resonant frequency of the sensor used. The AE ringdown counts (RDC) were used for correlation of AE activity with FCG behaviour. The cyclic stress intensity factor $\Delta K$ is calculated from the standard expression used for CT specimens (ASTM standard 1986). The crack growth rate ( $\mathrm{d} a / \mathrm{d} n)$ and the cumulative RDC $(N)$ were measured at different number of cycles $(n)$.

\section{Results and discussion}

Figure I shows a typical plot of cumulative $\operatorname{RDC}(N)$ as a function of number of cycles $(n)$ for one of the specimens. Almost negligible $\mathrm{AE}$ activity recorded in the initial stage (up to 50000 cycles) indicates that the interference of mechanical noise is insignificant. Figures. $2 \mathrm{a}$ and $\mathrm{b}$ show the plots of $\log (\mathrm{d} a / \mathrm{d} n)$ and $\log (N)$ as a function of $\log \Delta K$ for two specimens each in $25 \mathrm{~mm}$ and $12.5 \mathrm{~mm}$ thicknesses, respectively. The variation in $\log (\mathrm{d} a / \mathrm{d} n)$ with $\log \Delta K$ shows a linear behaviour for all the specimens. This linear behaviour has been fitted according to the Paris equation,

$$
\mathrm{d} a / \mathrm{d} n=C(\Delta K)^{m},
$$

where $C$ and $m$ are constants.

The $C$ and $m$ values for different specimens estimated from the above equation are given in table 1 . The variation in $\log (N)$ with $\log (\Delta K)$ shows a two-slope behaviour for all the specimens. This two slope behaviour indicates a change in the crack growth mechanism within the linear Paris regime, and suggest that the AE parameter like cumulative RDC can be used to distirguish the two subdivisions of the stage II crack propagation.

The presence of two substages IIa and IIb in stage II can be observed when one plots the variation in $\log (\mathrm{d} a / \mathrm{d} n)$ with $\log (n)$ (Gurevich and Eidorich 1974). Figures $3 \mathrm{a}$ and $\mathrm{b}$ show the variation in $\log (\mathrm{d} a / \mathrm{d} n)$ and $\log (N)$ as a function of $\log (n)$ for all the specimens. These figures show a two-slope behaviour for crack

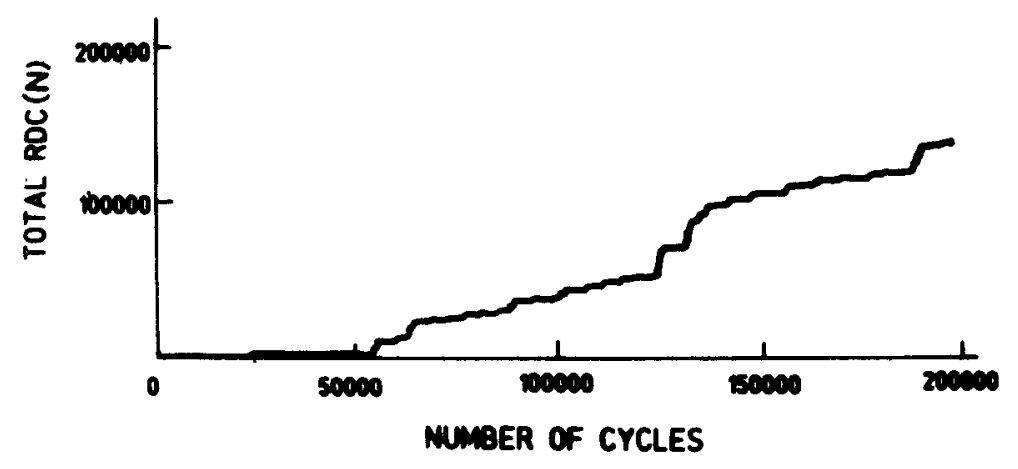

Figure 1. Typical variation of cumulative ruggdoun counts $(N)$ as a function of number of fatigue cycles $(n)$. 

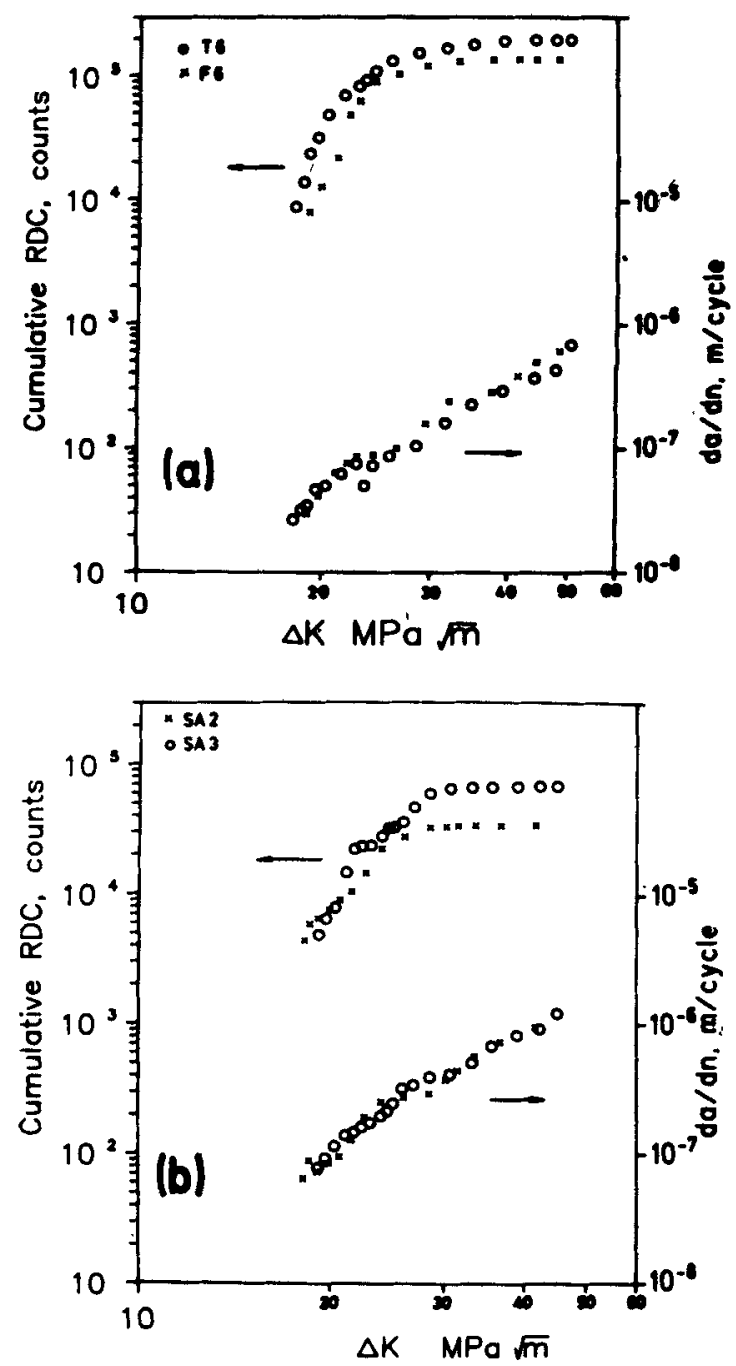

Figure 2. Variation of cumulative RDC and crack growth rate $(\mathrm{d} a / \mathrm{d} n)$ as a function cyclic stress intensity factor $(\Delta K)$ for (a) $25 \mathrm{~mm}$ and (b) $12.5 \mathrm{~mm}$ thick specimens.

propagation rate $(\mathrm{d} a / \mathrm{d} n)$ and $\mathrm{AE}$ cumulative $\mathrm{RDC}(N)$ during stage II FCG. The transition from stage IIa to IIb can be observed from the sharp increase in the slope of $\mathrm{d} a / \mathrm{d} n$ and a sharp decrease in $\mathrm{AE}$ activity after a certain number of cycles. The two slope behaviour shown by both the crack growth rate and $\mathrm{AE}$ activity itself is a direct evidence for a two-stage fatigue process during stage II. Some of the earlier studies (Morton et al 1973; Paul Mclintire 1987) showed a linear relationship between $\mathrm{AE}$ count rate (counts/cycle) and $\Delta K$. This may be due to collection of only peak load AE activity. Dunegan et al (1974) and Ohira 
et al (1980) observed a transition in peak load AE activity over a small range of $\Delta K$ in aluminium and steel and the same was attributed to the stress state change from plane strain to plane stress. Dunegan et al (1974) also showed that, after the transition, again $A E$ activity increases as the $\triangle K$ increases. This occurs even though the plane stress condition dominates at higher $\Delta K$. They could not explain the presence of this transition behaviour over a small $\Delta K$ range. Ohira et al (1980) attributed the high $\mathrm{AE}$ activity at lower $\Delta K$ to fracture events induced by the triaxial state of stress under plane strain condition. This explanation does not fully explain the scenario as the fracture events can also occur at higher $\Delta K$. In fact, the crack growth rate sharply increases only under plane stress condition at higher $\Delta K$. Also, the tensile deformation study on stainless steel using AET, reveals that the events like microvoid coalescence and microcrack growth occurring during necking process under triaxial state of stress do not generate detectable AE signals (Baldev Raj and Jayakumar 1991). In none of the FCG studies reported, the transition in AE behaviour was correlated in detail with the crack growth behaviour. In this study, an attempt has been made to relate the transition in $\mathrm{AE}$ behaviour with that of crack growth behaviour in the AISI type 316 stainless steel.

\subsection{Transition from stage IIa to IIb}

The coordinates for the transition point for changeover from stage IIa to IIb are given by the following two equations (Tanaka et al 1981):

$$
\begin{aligned}
\Delta K_{0} & =10 E b^{1 / 2}, \\
(\mathrm{~d} a / \mathrm{d} n)_{0} & =10^{3} b,
\end{aligned}
$$

where $\Delta K_{0}$ is the stress intensity at transition in MPa $\sqrt{m}, E$ the Young's modulus in $\mathrm{MPa}$ and $b$ the Burger's vector in $\mathrm{m}$ and $(\mathrm{d} a / \mathrm{d} n)_{0}$ the crack growth rate at transition in $\mathrm{m} /$ cycle.

The values of $\Delta K_{0}$ and (da/dn) $)_{0}$ for AISI type 316 stainless steel, predicted from the above equations using $E=193 \mathrm{GPa}$ (ASM Handbook 1968) and $b=2.5 \times 10^{-10}$ $\mathrm{m}$, are $30.5 \mathrm{MPa} \sqrt{\mathrm{m}}$ and $2.5 \times 10^{-7} \mathrm{~m} /$ cycle respectively which are close to the observed values as shown by table 2 . The transition from stage IIa to IIb has been observed to occur in this material when the crack growth rate reaches a value of $\sim 10^{-7} \mathrm{~m} /$ cycle which is in general agreement with the reported crack growth rate values at the transition (Grinberg 1982, 1984).

Table 1. Fatigue constants $C$ and $m$ for different specimens.

\begin{tabular}{lccc}
\hline \multirow{2}{*}{$\begin{array}{l}\text { Specimen } \\
\text { No. }\end{array}$} & $\begin{array}{c}\text { Thickness } \\
(\mathrm{mm})\end{array}$ & \multicolumn{2}{c}{ Fatigue constants } \\
\cline { 3 - 4 } & & $m$ & $C$ \\
\hline T6 & 25 & 2.82 & $9 \times 10^{-12}$ \\
F6 & 25 & 2.92 & $8 \times 10^{-12}$ \\
SA2 & 12.5 & 3.26 & $6 \times 10^{-12}$ \\
SA3 & 12.5 & 3.01 & $1.3 \times 10^{-11}$ \\
\hline
\end{tabular}



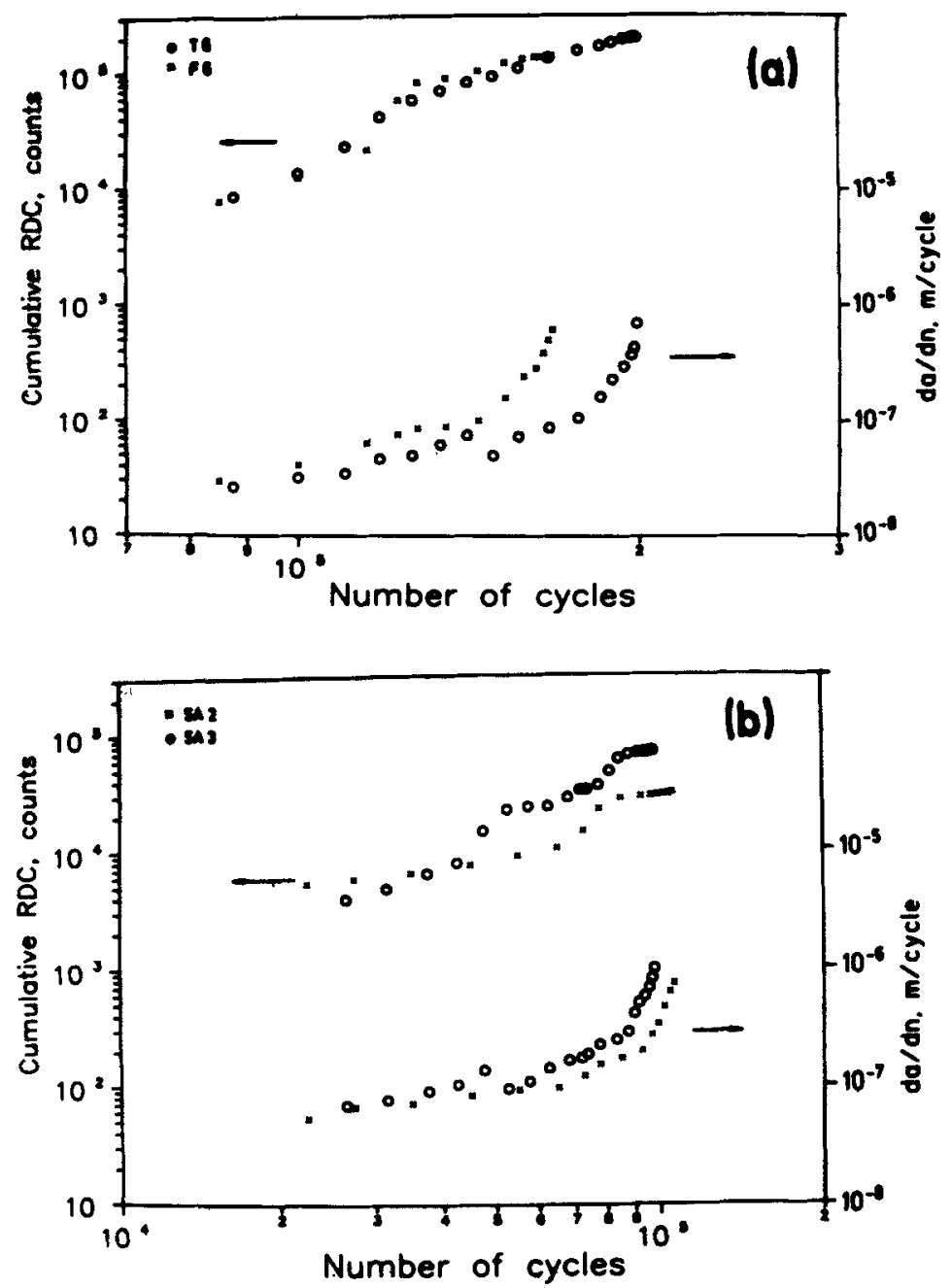

Figure 3. Variation of cumulative ringdown counts $(N)$ and crack growth rate $(\mathrm{d} a / \mathrm{d} n)$ as a function of number of fatigue cycles $(n)$ for (a) $25 \mathrm{~mm}$ and (b) $12.5 \mathrm{~mm}$ thick specimens.

The transition shown by the plots $\log (N)$ vs $\log (n)$ matches with that of $\log$ $(\mathrm{d} a / \mathrm{d} n)$ vs $\log (n)$ plot. Therefore, it can be reliably concluded that AET can be utilized for identification of the transition from stage IIa to IIb using $\log (N)$ vs $\log (n)$ plot during structural integrity monitoring applications where obtaining crack growth information is difficult in order to use the $\log (\mathrm{d} a / \mathrm{d} n)$ vs $\log (n)$ plot. The information on $\mathrm{AE}$ signals thus greatly helps in recognizing the transition essential for assessing the fatigue damage.

Figures $4 \mathrm{a}$ and $\mathrm{b}$ show the $\log -\log$ plots for variation in the RDC generated per unit crack extension $(\Delta N / \Delta a)$ with cyclic stress intensity factor $\Delta K$ for different specimens. $\Delta N / \Delta a$ was calculated by dividing the ringdown counts between two adjacent crack length measurements by the corresponding increment in the crack 
Table 2. Observed values of transition coordinates $(\Delta K)_{0}$ and $(\mathrm{d} a / \mathrm{d} n)_{0}$ for different specimens.

\begin{tabular}{lccr}
\hline $\begin{array}{l}\text { Specimen } \\
\text { No. }\end{array}$ & $\begin{array}{c}\text { Thickness } \\
(\mathrm{mm})\end{array}$ & $\begin{array}{c}\Delta K_{0} \\
(\mathrm{MPa} \sqrt{m})\end{array}$ & $\begin{array}{c}\text { (da/dn)0 } \\
(\mathrm{m} / \text { cycle })\end{array}$ \\
\hline F6 & 25 & 29.24 & $2.4 \times 10^{-7}$ \\
T6 & 25 & 28.05 & $2.25 \times 10^{-7}$ \\
SA2 & 12.5 & 28.16 & $3.7 \times 10^{-7}$ \\
SA3 & 12.5 & 30.39 & $3.08 \times 10^{-7}$ \\
\hline
\end{tabular}
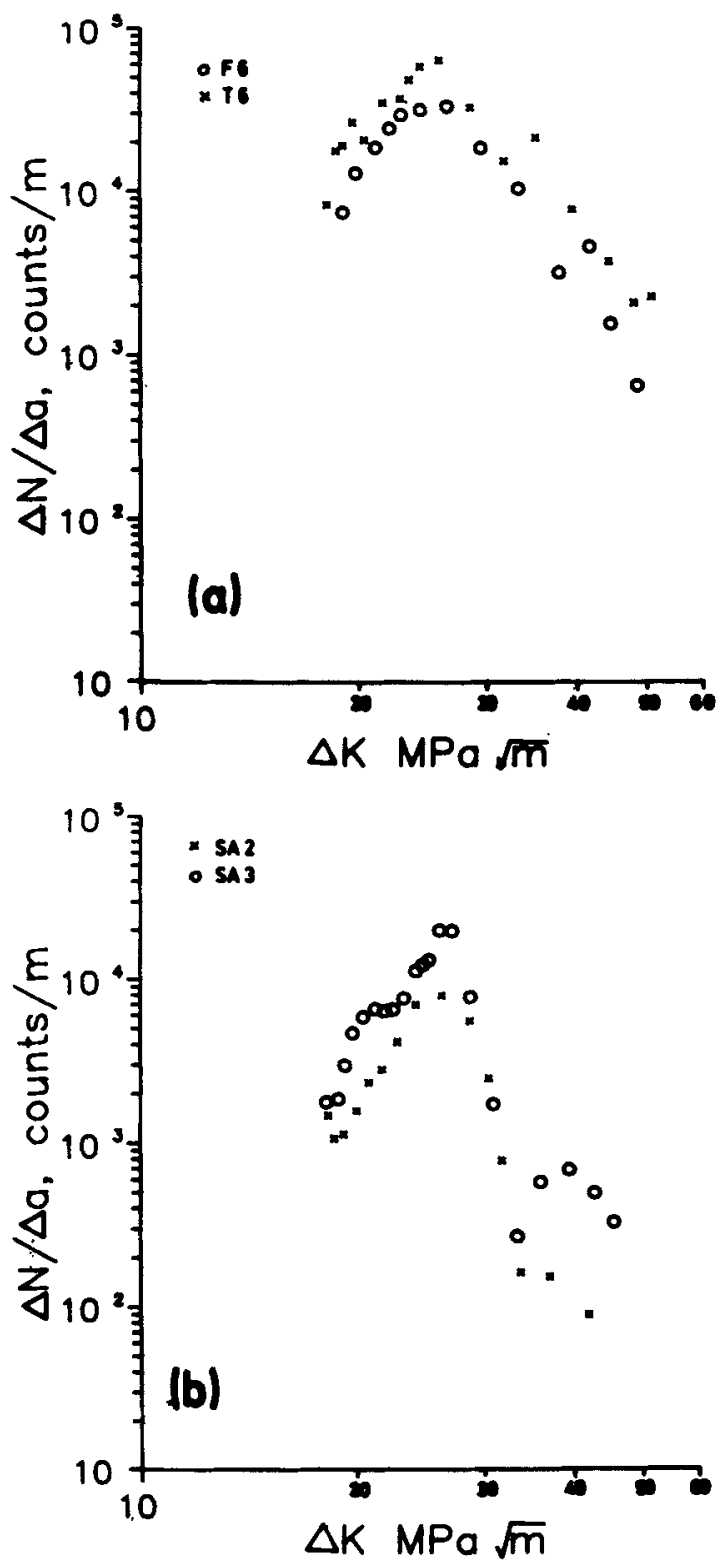

Figure 4. Variation of ringdown counts per unit extension of crack length $(\Delta N / \Delta a)$ as a function of cyclic stress intensity factor $(\Delta K)$ for (a) $25 \mathrm{~mm}$ and (b) $12.5 \mathrm{~mm}$ thick specimens. 
length. $\Delta N / \Delta a$ goes through a maximum with increase in $\Delta K$ indicating a transition. These plots also suggest that the $\log (N)$ vs $\log (\Delta K)$ plots in figures $2 \mathrm{a}$ and $\mathrm{b}$ appear flat during stage Ilb due to the logarithmic scale selection. It should be noted that significant $\mathrm{AE}$ is generated even during stage IIb. But, contrary to the sharp increase in $\mathrm{d} a / \mathrm{d} n$ there is a decrease in the rate of increase in $N$ after the transition point for all the specimens. This implies that the mechanism responsible for stage Ila gives higher $\mathrm{AE}$ as compared to the mechanism responsible for stage IIb. In order to understand this difference in $\mathrm{AE}$ behaviour, it is necessary to discuss the mechanisms of FCG and identify the major source of $\mathrm{AE}$.

According to Laird-Smith (1967) model, FCG during stage II occurs by crack tip blunting and resharpening mechanism during loading and unloading part of the fatigue cycle respectively. The crack growth mechanism is associated with plastic deformation, crack closure and crack jump near the crack tip. All these phenomena can contribute to $\mathrm{AE}$. In order to establish a better relationship between FCG behaviour and the $\mathrm{AE}$ behaviour, it is necessary to find out the major source of $\mathrm{AE}$ among these.

\subsection{Mechanisms of fatigue crack growth}

It has been observed that during the early part of stage II, each striation is formed not in one but in several loading cycles as against matching striations with number of loading cycles in the later part of stage II (Grinberg 1984). This difference in FCG behaviour has been explained by the following two mechanisms taking place in the early part (stage IIa) and later part (stage IIb) of stage II.

3.2a FCG mechanism during stage IIa: The effective stress intensity, $K_{\text {eff }}$ at the crack tip is given by

$$
K_{\text {eff }}=K_{\max }-K_{\text {ex }}
$$

where $K_{\max }$ is the stress intensity at maximum load, $P_{\max }$ and $K_{\mathrm{ex}}$ the stress intensities needed for crack extension.

For crack to extend, $K_{\text {eff }}>0$. Even in tension-tension fatigue cycle, compressive stresses are generated at the crack tip due to the displacement/stress field associated with the dislocations (Louat et al 1993). The region with compressive stress is known as reversed plastic zone or cyclic plastic zone (CPZ) (Suresh 1991). During stage $\Pi$, because of presence of compressive stress at the crack tip, $K_{\max }<K_{\text {ex }}$ and $K_{\text {eff }}<0$. Therefore, crack is unable to extend in the immediate next loading cycle. With progressive fatigue cycles, the compressive stress at the crack tip decreases slowly and becomes tensile after certain number of cycles. At this stage, the $K_{\text {eff }}$ becomes $>0$, thus enabling the crack to extend in the subsequent loading cycle.

3.2b FCG mechanism during stage IIb: At the transition point from stage IIa to IIb, the monotonic plastic zone size (MPZ) increases sharply. This results in microplastic instability produced by change in the degree of plastic constraint, i.e. 
from plane strain to plane stress condition. Under this condition, $K_{\max }$ is sufficiently larger than $K_{\mathrm{ex}}$ and hence, the crack growth is essentially controlled by $K_{\max }$ value. The compressive stress at the crack tip can easily be overcome during loading part of each cycle and therefore crack extension occurs in each cycle (Grinberg 1984). Hence, the crack growth rate sharply increases during stage IIb.

\subsection{Various sources of acoustic emission during fatigue crack propagation}

3.3a Ductile crack extension as a source of $A E$ : If the crack jump is considered as the main source of $\mathrm{AE}$, the cumulative RDC $(N)$ vs $\Delta K$ plot would have shown a linear relationship during entire stage II regime. But during stage $I \mathrm{Ib}$, the $\mathrm{AE}$ activity decreases (figure 4 ). If we calculate the minimum crack extension for a detectable AE signal to be emitted by a microcrack for a stainless steel, according to the theory suggested by Scruby et al (1981), it would be approximately $1 \mu \mathrm{m}$. It is generally observed that for iron and steels, the striation spacing is less than $0.5 \mu \mathrm{m}$ for $\mathrm{d} a / \mathrm{d} n<10^{-7} \mathrm{~m} /$ cycle (Roven et al 1991) which is smaller than minimum needed for generating detectable AE. Pickard et al (1975) also had observed that the microcrack growth rate in AISI $316 \mathrm{SS}$ is $\simeq 0.52 \mu \mathrm{m} /$ cycle at $\Delta K \approx 28 \mathrm{MPa} \sqrt{m}$. The fracture process is found to occur within the process zone near the crack tip. The length of the process zone in the direction of crack propagation is given by (Moura Branco et al 1989),

$$
R_{\mathrm{pz}}=\Delta K^{2} / 8 E \sigma_{\mathrm{yc}}
$$

where $\sigma_{y c}$ is the cyclic yield stress.

From the above equation, the size of the process zone itself is $\simeq 1 \mu \mathrm{m}$ at $\Delta K \cong 25 \mathrm{MPa} \sqrt{m}$ and the number of cycles required for the complete failure of the process zone is few tens of cycles. Hence, the crack extension at any instant is expected to be much smaller than $1 \mu \mathrm{m}$ during stage Ha. Therefore, it is inferred that ductile crack growth process does not generate detectable AE during stage IIa. However, it has the possibility to contribute to $\mathrm{AE}$ activity at higher $\Delta K$ during stage IIb.

3.3b Crack closure as a source of $A E$ : Generally, the crack closure phenomenon is observed to be dominant near the threshold and stage I FCG regions. Its effect is less pronounced during stage II propagation under mode I loading condition. The plasticity induced crack closure is considered essentially as a plane stress effect (Arthur McEvily 1988) and its effect can be observed under plane strain only when the $R$ ratio approaches zero. During stage IIa, the major portion of the thickness is under plane strain condition. Hence, this type of closure is only a surface phenomenon. Recently, Louat et al (1993) have shown from an analytical estimation using dislocation theory that the plasticity induced crack closure cannot occur during unloading part of the cycle. Asperity or roughness induced crack closure results from the mismatch between the two crack surfaces during unloading (Arthur McEvily 1988). This is promoted by low $\Delta K$ when the size of the process zone is less than the grain size and in presence of microstructure consisting of coarser grains, shearable and coherent precipitates (Suresh 1991). In this study, a nuclear grade 
316 stainless steel with almost negligible inclusion content was used under solution treated condition. Therefore, the contribution from this roughness induced crack closure is likely to be absent or negligible. The lower $\mathrm{AE}$ activity at the early part of the fatigue cycling (figure 1) also clearly supports the fact that the influence of crack closure on $\mathrm{AE}$ is not significant in the present study. It is clear from the above discussions that the ductile crack extension or the crack closure are not likely to be the major sources of AE during stage II FCG. Hence, the plastic deformation near the crack tip as a major source of AE needs serious consideration.

3.3c Plastic deformation as a source of $A E$ : It has been suggested that spontaneous dislocation generation (Rice and Thompson 1974), and higher mobility of the dislocations (Neumann et al 1979) near the crack tip leads to the crack tip blunting and subsequent crack propagation in a ductile manner. Thus, crack propagation is highly sensitive to dislocation mechanism that is occurring near the crack tip region. The plastic deformation zone ahead of a fatigue crack can be divided into three regions (Guerra Rosa et al 1984): (i) monotonic plastic zone (MPZ), (ii) cyclic plastic zone (CPZ) which lies within the MPZ, and (iii) process zone or crack tip opening displacement (CTOD) affected zone within the CPZ.

(i) Monotonic plastic zone as a source of $A E$ : Under both plane stress and plane strain conditions, the size of the MPZ is proportional to the square of $\Delta K$ under fatigue loading (Suresh 1991). Therefore, if the deformation in the MPZ is considered as the main source of $\mathrm{AE}$, the $\mathrm{AE}$ activity should increase with increase in $\Delta K$ even during stage IIb like that observed in stage IIa. However, it is observed experimentally during the present study that the RDC per unit crack extension decreases $(\Delta N / \Delta a)$ with increase in $\Delta K$ during stage IIb (figure 4). The deformation in the MPZ can be considered to obey the Kaiser effect (Palmer 1973), i.e. the AE can be generated only from the region where the stress value increases over previous value due to the crack extension. Therefore, the AE activity from the MPZ expansion can arise only from a thin zone at the elastic-plastic boundary. But in FCG of metals, even during stage IIb at a crack growth rate of $1 \mu \mathrm{m}$ per cycle, the increment in the size of MPZ after each crack extension (a) is less than $1 \mu \mathrm{m}$ and hence, is too small to generate detectable AE. In addition, during stage IIa of FCG, since, crack growth is not expected to occur in each cycle, the MPZ expansion does not occur in each loading cycle. Therefore, the occurrence of higher AE activity in stage Ia as compared to stage IIb indicates that the MPZ expansion may not be the major source of $\mathrm{AE}$ during FCG.

(ii) Cyclic plastic zone as a source of $A E$ : In FCG process of metallic materials, cyclic plasticity is supposed to occur only within CPZ (Moura Branco et al 1989). An element in the material within this zone is subjected to hysteresis loops similar to those observed in a low cycle fatigue test. The size of the CPZ is given as (Guerra Rosa et al 1984),

$$
R_{c p z}=\alpha_{c}\left(\Delta K / \sigma_{y s}\right)^{2},
$$

where $\sigma_{y s}$ is the monotonic yield stress and $\alpha_{c}$ is the coefficient of CPZ. As a source volume of $\mathrm{AE}$, the size of the $\mathrm{CPZ}$ is much larger than the crack growth 
area, crack closure area and the increment in the MPZ volume after each crack jump. Earlier studies (Hahn et al 1972; Guerra Rosa et al 1984) have shown that, in the Paris regime of FCG, the $\mathrm{CPZ}$ generally experiences strain cycles with plastic strain range between $10^{-3}$ and $10^{-1}$. Eventhough the size of the $\mathrm{CPZ}$ is smaller than the size of the MPZ, the cyclic plasticity within the CPZ occurs during each cycle and is associated with extensive dislocation generation and rearrangement. There is a continuous dislocation substructure development within the $\mathrm{CPZ}$ associated with the variation in the cyclic saturation stress and the plastic strain range. The substructure evolution with increasing number of cycles is well investigated by Roven and Nes (1991). The substructure evolution occurs in various stages from the CPZ boundary to crack tip: first the development of dislocation walls and veins near the CPZ boundary, then to a labyrinth structure, dislocation cells inside the CPZ and finally to banded cells and subgrains in the regions close to the crack tip. This involves extensive dislocation mobility within the CPZ. Tensile deformation study on cold worked AISI 316 stainless steel has shown that the deformation in the presence of the dislocation substructure generates higher $\mathrm{AE}$ activity as compared to a solution annealed material during pre-yield deformation (Moorthy et al 1994). It has been observed that the pre-yield AE activity increases with increase in percentage prior to cold work. This behaviour has been explained using the composite deformation model applied for the deformation of dislocation substructure. Therefore, dislocation substructure deformation during the cyclic plasticity within the $\mathrm{CPZ}$ could be a major source of AE during FCG.

\subsection{AE behaviour during stages IIa and IIb}

It is observed from figures 2 and 4 that the AE activity increases with increase in $\Delta K$ during stage IIa and decreases during stage IIb. The detailed discussions made earlier point towards the interpretation that $\mathrm{CPZ}$ could be a major source of AE during FCG in this material. It has been observed that the CPZ in a FCG process is always generated and developed under plane strain conditions (Moura Branco et al 1989). The measurements of CPZ sizes using etching technique in Fe-3\%Si steel (Hahn et al 1972) and that using microhardness technique in medium strength steel (Guerra Rosa et al 1984) have indicated that the coefficient of CPZ size $\alpha_{c}$ has larger value under plane strain conditions than that under plane stress conditions. The size of CPZ computed from the effective strain range distribution in aluminium alloy (Davidson and Lankford 1983) has also indicated that the size of the CPZ decreases with increase in $\Delta K$ under plane stress condition. Therefore, for a given $\Delta K$, the size of the $\mathrm{CPZ}$ under plane strain condition is larger as compared to that under plane stress condition.

During stage IIa, the plane strain condition dominates the major portion of the specimen thickness. As the coefficient of CPZ size increases under plane strain condition, the net volume of the CPZ is expected to increase with $\triangle K$. Hence, the $\mathrm{AE}$ activity increases during stage IIa. The plane stress condition dominates when the size of the monotonic plastic zone becomes greater than one fourth of the specimen thickness (Hamel et al 1981; Grinberg 1984). This occurs at $\Delta K \simeq 30 \mathrm{MPa} \sqrt{m}$ for the stainless steel specimens studied by us. The transition from stage Ila to IIb also occurs around the same $\Delta K$ value. Due to decrease in 
the coefficient of $C P Z$ size under plane stress condition, the increment in volume of the CPZ cannot be large enough to emit significant AE. The size of the CPZ would also decrease with increase in $\Delta K$ under plane stress conditions as observed by Davidson and Lankford (1983). In addition, the plastic strain range in CPZ increases at higher $\Delta K$ values (Roven and Nes 1991). It is also known that as the crack length increases, strain intensification occurs in the plastic zone (Navarro and De Los Rios 1992). Therefore, the mobility and mean free path of the dislocations are much reduced at higher $\Delta K$. Hence, there is a reduction in the extent of cyclic plasticity. As a result, the AE activity is expected to decrease during stage IIb. It can thus be concluded that the $\mathrm{AE}$ behaviour during stage II FCG depends to a significant degree on the increment in the size of CPZ and the strain range within $C P Z$.

According to cumulative damage theory of FCG, the material near the crack tip strain hardens progressively with number of cycles until the stress at the crack tip reaches a critical value for crack extension (Davidson and Lankford 1983). The strain hardening near the crack tip region mainly occurs by cyclic deformation. It is also observed that the number of cycles required for each crack extension decreases with increase in $\Delta K$ (Roven and Nes 1991). This is due to the fact that the plastic strain range at the crack tip is strongly dependent on $\Delta K$ and therefore, more number of cycles are required to attain the critical strain for crack extension at lower $\Delta K$. Therefore, during stage IIa, we can expect that more energy is dissipated by the cyclic plasticity which results in more AE activity. Since, strain intensification occurs progressively in the plastic zone as the crack length increases, the critical strain near the crack tip can be reached in each cycle during stage IIb. At higher $\Delta K$, the crack growth is essentially controlled by $K_{\max }$ value. Therefore, the energy dissipation by plastic deformation is reduced and hence, the AE activity also decreases. From the above discussions, it becomes obvious that $A E$ during FCG strongly depends on the size of CPZ, the plastic strain range and the number of cycles required for each crack extension.

\subsection{An empirical model to relate $A E$ and $\Delta K$ during stage IIa}

Detectable AE activity is generated only in the presence of substantial dislocation mobility, which exists under the condition of optimum plastic strain range (of the order of $10^{-3}$ to $10^{-2}$ ). Very low as well as very high strain could not generate detectable AE due to reduced dislocation mobility. The cyclic plasticity occurs with the cyclic strain range of $10^{-3}$ to $10^{-1}$ (Guerra Rosa et al 1984). The optimum combination of volume of $\mathrm{CPZ}$ and the plastic strain range to generate significant AE prevails only during stage IIa. Therefore, AE RDC generated at a given $\Delta K$ before each crack jump should depend on the product of volume of CPZ and the plastic strain range with which the cyclic plasticity occurs. Since, the number of cycles required to attain critical strain for crack extension is a function of $\Delta K, \mathrm{AE}$ RDC generated at given $\Delta K$ can be assumed to be proportional to the number of cycles required before each crack extension.

The volume of $\mathrm{CPZ}$ is given as

$$
V_{\mathrm{cpz}}=\pi * R_{\mathrm{cpz}}^{2} * B,
$$


using (6) for $R_{\mathrm{cpz}}$,

$$
V_{\mathrm{cpz}}=\pi * B * \alpha_{\mathrm{c}}^{2} *\left(\Delta K / \sigma_{\mathrm{ys}}\right)^{4}
$$

where $R_{\text {cpz }}$ is the radius of CPZ, $\alpha_{c}$ the coefficient of CPZ size, $B$ the thickness of the specimen and $\sigma_{y s}$ the yield stress.

The plastic strain range within the CPZ is given as (Jacques Lantegne and Jean Paul-Bailon 1981)

$$
\Delta \varepsilon_{\mathrm{p}}=\frac{0.4\left(1-v^{2}\right) \Delta K^{2}}{\pi \sqrt{3} \cdot c \cdot x \cdot \sigma_{y s} \cdot E},
$$

where $x$ is the distance from the crack tip, $c$ is a triaxiality factor, $v$ the Poisons' ratio and $\sigma_{y s}$ the monotonic yield stress. Eventhough the plastic strain range is a function of the distance from the crack tip, as a simplification, we assume that this is an average plastic strain range:

Let us assume that each crack jump occurs by complete rupture of the process zone. The number of cycles required for the failure of the process zone is given by

$$
N_{\mathrm{f}}=R_{\mathrm{pz}} /(\mathrm{d} a / \mathrm{d} n)
$$

where, $R_{\mathrm{pz}}$ the size of the process zone is given by (5).

It follows that the number of RDC generated by the cyclic plasticity before the next crack jump is given as

$$
N \propto\left(V_{\mathrm{cpz}} * \Delta \varepsilon_{\mathrm{p}}\right) * N_{\mathrm{f}}
$$

Substituting for $V_{\mathrm{cpz}}, \Delta \varepsilon_{\mathrm{p}}$ and $N_{\mathrm{f}}$ from (8), (9) and (10) respectively, we get,

$$
N \propto\left(\Delta K^{4} * \Delta K^{2}\right) * \Delta K^{2} /(\mathrm{d} a / \mathrm{d} n) \text {. }
$$

Considering that $\mathrm{d} a / \mathrm{d} n \simeq C \Delta K^{3}$ for this material (table 1),

$$
N \propto \Delta K^{s}
$$

The crack propagation process can be considered as a cumulative growth process due to incremental increase in crack length. After each crack jump, there is an increment in $\Delta K$. It represents only the cumulative effect. The increment in $\Delta K$ gives rise to an increment in the volume of $\mathrm{CPZ}$ and hence, an increment in $\mathrm{AE}$ counts. Therefore, it is more appropriate to relate the cumulative $\mathrm{AE}$ ringdown counts with $\Delta K$. As already mentioned, the number of cycles required for each crack extension is more than one during stage $\amalg \mathrm{a}$ and is equal to one during stage IIb. Therefore, for a given increment in crack length, the counts per cycle will always give lower value during stage $\Pi$ Ia as compared to stage IIb. Hence, counts/cycle is not an appropriate parameter. According to (13), during stage IIa, the plot of cumulative RDC vs $\Delta K$ should show a slope of 5 . Since, the transition from stage IIa to IIb is found to occur at $\sim \Delta K=30 \mathrm{MPa} \sqrt{m}$. The data up to $=30 \mathrm{MPa} \sqrt{m}$ have been considered for the calculation of the slope and is shown 
in figures $5 \mathrm{a}$ and $\mathrm{b}$ for all the samples. The value of the slope and the correlation coefficient of the best fit for different samples are shown in table 3 . There is a good agreement between the experimentally observed values and the predicted value of the exponent in (13). Even when we consider the statistical behaviour of $\mathrm{AE}$ activity, the correlation coefficient indicates that the fit is reasonably good.
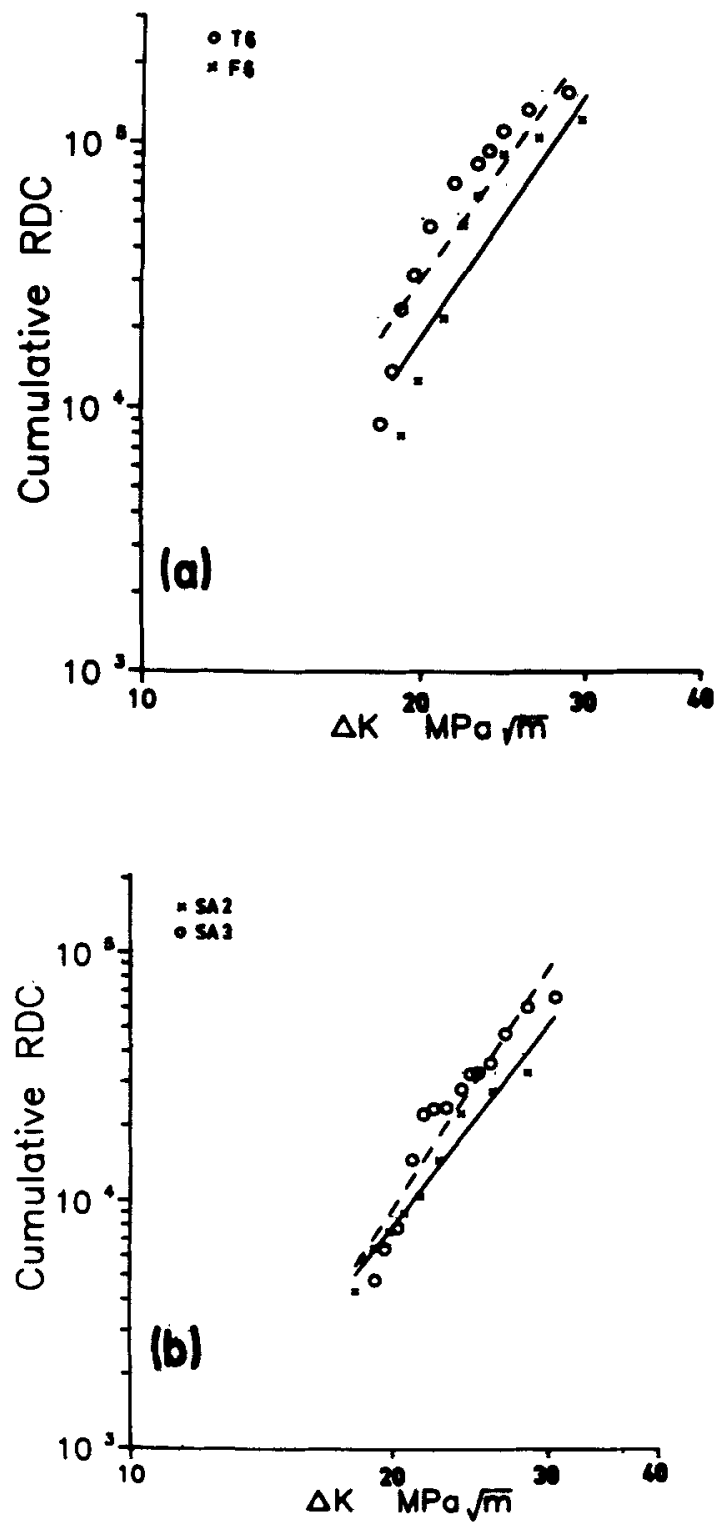

Figure 5. Variation of cumulative ringdown counts $(N)$ as a function of cyclic stress intensity factor $(\Delta K)$ during stage Ila FCG for (a) $25 \mathrm{~mm}$ and (b) $12.5 \mathrm{~mm}$ thick specimens. 
Table 3. The slope of $\log$ cumulative RDC vs $\log \Delta K$ plot during stage IIa for different samples.

\begin{tabular}{lccc}
\hline $\begin{array}{l}\text { Specimen } \\
\text { No. }\end{array}$ & $\begin{array}{c}\text { Thickness } \\
(\mathrm{mm})\end{array}$ & $\begin{array}{c}\text { Slope of } \\
\text { cumulative } \\
\text { RDC vs } \Delta K \text { plot }\end{array}$ & $\begin{array}{c}\text { Correlation } \\
\text { coefficient }\end{array}$ \\
\hline T6 & 25 & 4.99 & 0.83 \\
F6 & 25 & 5.22 & 0.81 \\
SA2 & 12.5 & 4.54 & 0.97 \\
SA3 & 12.5 & 5.39 & 0.90 \\
\hline
\end{tabular}

\section{Conclusions}

Acoustic emission technique has been used for detecting the transition from stage IIa to IIb in the Paris region. As there is no need for crack growth measurement for determining the transition, use of AET during structural integrity monitoring can effectively predict the sharp increase in crack growth rate and ensures avoidance of catastrophic failures. Among the various possible sources of AE, detailed discussions presented in this paper have established that the cyclic plasticity within the cyclic or reversed plastic zone is the main source of AE during FCG. Considering AE activity dependence on the volume of cyclic plastic zone and the plastic strain range, it has been predicted as well as experimentally observed that the cumulative $\mathrm{RDC}$ is proportional to the fifth power of $\Delta K$ during stage IIa.

\section{Acknowledgements}

Authors are thankful to $\operatorname{Dr} C \mathrm{R} \mathrm{L}$ Murthy and Mr M R Bhat, Indian Institute of Science, Bangalore for their support in carrying out fatigue testing of the specimens. Authors are thankful to Shri D K Bhattacharya, Deputy Director, National Metallurgical Laboratory, Jamshedpur, for discussions. Authors are thankful to Dr Placid Rodriguez, Director, Indira Gandhi Centre for Atomic Research, Kalpakkam, for constant encouragement and support.

\section{References}

Arthur McEvily J 1988 ASTM STP-982 p. 35

ASM Metals Handbook 1968 Properties and selection of materials (USA: ASM) 8th Edn. p. 423

American Society for Testing and Materials 1986 Standard test method for constant-load-amplitude fatigue crack growth rates above $10^{-8} \mathrm{~m} /$ cycle, ASTM E-647 (USA: ASTM)

Birkheck G, Inckle A E and Waldron G W J 1971 J. Mater. Sci. 4319

Baldev Raj and Jayakumar T 1991 ASTM STP-1077 p. 218

Daniel Smith R and Carpenter S H 1988 J. Acoust. Emission 79

Davidson D L and Lankford J 1983 ASTM STP-811 p. 371

Dunegan H L and Tetelman A S 1971 Engg. Fract. Mech. 2387

Dunegan H L, Harris D O and Tatro C A 1968 J. Engg. Fract. Mech. 1105

Dunegan H L, Harris D O and Tetelman A S 1970 Mater. Eval. 28221

Gerberich W W and Hartbower C E 1967 Int. J. Fract. Mech. 3185

Grinberg G M 1982 Int. J. Fatigue 483

Grinberg G M 1984 Int. J. Fatigue 6229 
Guerra Rosa L and Radon J C 1989 Advances in fatigue science and technology (eds) C Moura Branco and L Guerra Rosa (Netherlands: Kluwer Academic) p. 141

Guerra Rosa L, Moura Branco C and Radon J 1984 Int. J. Fatigue 617

Gurevich S E and Edidorich L D 1974 Fatigue and fracture toughness of metals (Moscow, USSR: Nauka) p. 36

Hahn G T, Hoagland R G and Rosenfield A R 1972 Metall. Trans. A3 1189

Hamel F, Bailon J P and Bassim M N 1981 Engg. Fract. Mech. 14853

Harris D O and Dunegan H L 1974 Exp. Mech. 271

Hartbower C E, Gerberich W W and Liebowitz H 1968 Engg. Fract. Mech. 1291

Hartbower C E, Reuter W G, Morais C F and Crimmins P O 1972 ASTM STP 505 p. 187

Heiple C R and Carpenter S H 1987 J. Acoust. Emission 6177

Hideo Kusanagi, Hideo Kimura, Hiromasa Imaeda, Tadao Ishihara and Shigeo Ohashi 1980 Proc. of the 5th int. acoustic emission symposium, Tokyo p. 125

Jacques Lantegne and Jean-Paul Bailon 1981 Metall. Trans. A12 459

Laird C and Smith G C 1967 Philos. Mag. 7847

Lindley T C, Palmer I G and Richards C E 1978 Mater. Sci. Engg. 321

Louat N, Sadananda K, Duesbery M and Vasudevan A K 1993 Metall. Trans. A24 2225

Masuda C, Ohta A, Nishijima S and Sasaki E 1980 J. Mater. Sci. 151663

Moorthy V, Jayakumar T, Bhattacharya D K and Baldev Raj 1991 Proc. int. symp. on fatigue and fracture of steel and concrete structures, Madras 1219

Moorthy V, Jayakumar T and Baldev Raj 1994 To be published

Mori Y, Sahakibara Y, Nagata T, Ohira T and Kishi T 1980 Proc. of the Sth AE symp., Tokyo p. 465

Morton T M, Harrington R M and Bjelectich I G 1973 Engg. Fract. Mech. 5691

Navarro A and De Los Rios.E R 1992 Proc. R. Soc. London A437 375

Neumann P, Fuhlrott $H$ and Vehoff $H 1979$ ASTM STP-675 p. 371

Ohira T, Kishi T and Horeuchi R 1980 Proc. of the Sth int. AE symp. Tokyo p. 137

Palmer I G 1973 Mater. Sci. Engg. 11227

Paul Mclintire 1987 Non-destructive testing handbook, acoustic emission testing (American Society for NDT) 2nd edn., p. 49

Pickard A C, Ritchie R O and Knott J F 1975 Metals Tech. 6253

Rice J R and Thompson R 1974 Philos. Mag. 2973

Roven H J and Nes E 1991 Acta Metall. 391735

Sturdy C B, Jones C, Titchmarch J M and Wadley H N G 1981 Metal. Sci. 6241

Suresh S 1991 Fatigue of materials (Cambridge: Cambridge University Press) p. 162

Tanaka K, Masuda C and Nishijima S 1981 Scr. Metall. 13259

Wang Z F, Li J, Ke W, Zheng Y S, Zhu Z and Wang Z، G 1992 Scr. Metall. 271691 